Pathologe 2012 ·33:161

DOI 10.1007s00292-012-1570-3

(c) Springer-Verlag 2012

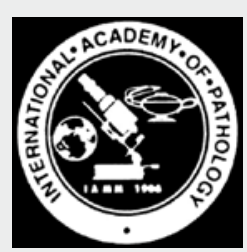

\section{Deutsche Abteilung}

der Internationalen Akademie für Pathologie e.V.

Geschäftsstelle

Auguststr. 19-29, 53229 Bonn

Tel.: 0228-28 2404

Fax: 0228-28 4796

E-Mail: martina.schmidt@iap-bonn.de

Internet: www.iap-bonn.de

\title{
5th International Junior Academy Summer School
}

\section{On behalf of the German and British Divisions of the IAP July 1-4, 2012, Dublin, Ireland}

The German and British Division welcomes you to the 5th International Junior Academy Summer School, this year being held in the beautiful seaside location of Portmarnock just outside Dublin.

This annual Summer School is aimed primarily at young pathologists. Selected topics will be discussed in depth by experts and participants are encouraged to fully participate in all the sessions and to meet and have discussions with the experts. The School also provides the unique opportunity for participants to meet with other young pathologists from many countries and to exchange ideas.

\section{Meeting Venue:}

Portmarnock Hotel \& Golf

Links Strand Road,

Portmarnock, Dublin

Phone: +3531846 o611

FAX: +35318462442

E-Mail: info@portmarnock.com www.portmarnock.com

\section{Organisation Committee}

Professor Martin-Leo

Hansmann, M.D. (Frankfurt)

Professor Kristin Henry, M.D.

(London)

Professor Mary Leader, M.D.

(Dublin)

\section{Organisation Office}

The detailed programme may be obtained from:

Martina Schmidt

International Academy of

Pathology

German Division Inc.

Auguststr. 19-29, 53229 Bonn

Phone: +49(o)228 282404

Fax: +49(o)228 284796

E-Mail: martina.schmidt@iapbonn.de 